\title{
Report on Workshop Discussions
}

\section{B) Resource Management, Field Tools and Tactics}

\section{by}

I.D. Bird ${ }^{1}$

This has been an interesting exercise for me and I hope for many of you. It reminds me of a high school dance. We all started on Monday evening on opposite sides of the room, The government people on one side and the industry people on the other with those who represent neither industry, or government up at the bar! As the event progressed we have seen some coming together, some tentative steps across the floor and some encounters culminating in the workshop sessions where we had a fairly well balanced representation of the interested groups. It has been a worthwhile experience and perhaps it will go beyond the close of the high school dance to some of the real fun things that happened afterwards.

Our group was talking about tools and tactics or implementation. Our objective was to recommend some improvements in the process. The first subject we covered was information and particularly information needs. There was pretty clear consensus that we need a wildlife inventory to some acceptable degree of precision. We recognized some parallels here with timber management. Foresters feel smug sometimes about their achievements in inventory but I do not think this is justified. We also need to establish quantified population objectives and we need to know the habitat requirements quantified in terms of cover and forage. And finally we need better information on the results of our interventions both in biological and economic terms.

All of this led us to consider the need for an improved data base and there was some real sympathy for developing a common data base for the management of both timber and wildlife. We recognized that modern geographic information systems provide the means for doing this and that we should be making better use of them. This would likely involve the harmonization of unit boundaries for wildlife and forestry. A lot of administrative and perhaps some legal problems are inherent in this but in spite of these problems there are clear opportunities for harmonization that we should seek out.

Better circulation of information is another requirement and we need to focus here on technological development and technological transfer. An important factor that will drive a lot of these changes is the requirement for environmental assessment of forest land management. Many people are looking forward to this and what will be provided in the way of

1President, Ontario Forest Industries Association, Toronto effects monitoring. It will give us an opportunity to gain information about some of the things that otherwise would have remained obscure and to ensure that this information flows freely to those interested and affected.

In discussing implementation it is hard to avoid touching on policies and guidelines. There was some concern about guidelines becoming too rigid. The group felt that intimate knowledge of the management unit is required for effectively managing wildlife, timber, dickybirds, butterflies, frogs, or even mosquitoes. With that knowledge the field officer deserves to have the authority to make the judgement calls required; to perhaps stray a little bit from the guidelines and to do what is right in the specific situation. It is called accountability and its importance was highlighted in Dr. Baskerville's review of forest management in Ontario.

On the subject of communication, the group stressed the importance of communicating effectively with the public on the benefits of integrated resource management which so far has focussed mostly on timber and wildlife but which should lead ultimately to a broader eco-system approach dealing with recreation and other values. Just as important, if not more so, is the need to improve communications between disciplines and we have made some progress in that direction here over the last few days. We need to improve communication between government and industry and I suppose we always shall. Many of us are working towards it and I think we can look forward to improvements.

Another important area is the need for management to communicate with the front line workers. Government needs to communicate with their professionals and in turn the professionals must have open lines to their technicians. Similar procedures are just as important in the industry. It is important that all members of a team understand what the objectives are.

A number of research needs were identified in our discussions. We thought that much information must be available after all the research that has been going on for many years but that much of it has not yet been published and is not readily available. The quality of science and the importance of good experimental design in the biological sciences was also discussed. One suggestion was that we should try to adapt to wildlife management the approach used in fisheries with their Fisheries Assessment Units and design a wildlife assessment unit. The group concluded that there is also much experience and history that we are not using. We 
have heard about the lack of knowledge on the long-term effects of logging,but remember that timber harvesting has been going on around Iroguois Falls and Kapuskasing for over 60 years. There must be a lot of history there that we could use to better advantage.

Our discussions then turned to the question of who pays? Before we can answer that question we have to know what needs to be paid for. You heard Mike Opper say this morning that he was from Missouri when it comes to some of the demands being made in the name of wildlife management. Before we go into special prescriptions for wildlife we have to have some demonstrated results from the use of similar prescriptions to be convinced that it is a good thing to do. We also need to know how much it is going to cost before we answer the question of who pays. But when all of these things are known you still come up with the obvious conclusion that the costs will be shared by the industry, the taxpayer and the user of the products in some appropriate proportion. I think the costs should be assigned to those who benefit. Of course the reason we talk so much about who pays is that industry gets concerned about additional costs and governments get concerned about additional funding requirements. Perhaps we can learn again from the fisheries model. I understand that revenue derived from fishing licenses is now earmarked for fisheries work. I saw recently in the weekly newspaper in the
Algonquin region where I live, a listing of all the fisheries restoration projects that have been undertaken there. I tell you that was an excellent marketing job. They do not just put out some rubble on the beach somewhere to improve spawning beds, they use limestone rubble and people concerned about acid rain are pleased. That is good marketing and I am sure there is much we can do similarly to overcome our funding problems.

Finally in our group we spoke about integration. It is a great buzzword that we have heard a lot about in the last two days and in the last few years. There have been some real integration successes in recent times. The integration of timber harvesting with silviculture has produced some extremely favourable results and we should look further at this. That kind of integraiton achieved good results because quantified objectives were clearly established at the outset. There were standards of performance established and there was an understanding between the agreeing parties on schedules of payment for work done. One of the most important things was that there was an arrangement for monitoring performance with renewal of the agreement predicated on attaining the objectives. Perhaps we have an opportunity now to build on that success and to go a step further to integrate wildlife management with forest management. 